\title{
A 14-day course of triple therapy is superior to a 10-day course for the eradication of Helicobacter pylori: A Canadian study conducted in a 'real world' setting
}

\author{
Yen-I Chen MD, Carlo A Fallone MD
}

\begin{abstract}
Y-I Chen, CA Fallone. A 14-day course of triple therapy is superior to a 10-day course for the eradication of Helicobacter pylori: A Canadian study conducted in a 'real world' setting. Can J Gastroenterol Hepatol 2015;29(8):e7-e10.
\end{abstract}

BACKGROUND: Successful Helicobacter pylori eradication with the traditional seven-day course of proton pump inhibitor (PPI) triple therapy is declining. Prolonging therapy to either 10 or 14 days is associated with better eradications rates.

OBJECTIVE: To compare the effectiveness of 14-day course of triple therapy versus a 10-day course in the treatment of $\mathrm{H}$ pylori in Canada. METHODS: Consecutive treatment-naive patients with clinical indications for $\mathrm{H}$ pylori eradication underwent either a 10-day course or a 14-day course of traditional PPI triple therapy depending on the date of the office visit (an odd date received the 10-day course, whereas an even date received the 14 -day treatment). $H$ pylori eradication was ascertained via urea breath test or gastric biopsies performed $\geq 4$ weeks after completion of therapy. Analyses were by both intention to treat and per-protocol.

RESULTS: A total of 83 patients were included in the study ( 31 in the 10 -day group and 52 in the 14-day group). In the intention-to-treat analysis, eradication rates were $82.7 \%$ (95\% CI $70 \%$ to $92 \%$ ) versus $45.2 \%$ (95\% CI $27 \%$ to $64 \%$ ), favouring the 14 -day treatment $(\mathrm{P}<0.001)$. Similarly, in the per-protocol analysis, eradication rates were $91.5 \%$ (95\% CI $80 \%$ to $98 \%$ ) versus $63.6 \%$ (95\% CI $41 \%$ to $83 \%)$, favouring the 14 -day arm $(\mathrm{P}=0.01)$. Adverse events and compliance were not significantly different between the two groups.

CONCLUSION: A 14-day course of standard PPI triple therapy was superior to a shorter-duration therapy and should be included as a firstline regimen for $\mathrm{H}$ pylori eradication in Canada. The 10-day course of treatment did not achieve an acceptable eradication rate and should no longer be used in this country.

Key Words: Helicobacter pylori; Duration; PPI triple therapy; Treatment

Telicobacter pylori is a common infection worldwide (1); however, 1 most affected individuals are asymptomatic and are often unaware of the diagnosis. The importance of $\mathrm{H}$ pylori as a pathogenic organism first became apparent when Marshall and Warren (2) linked the Gramnegative bacteria with peptic ulcer disease. Since that time, $H$ pylori has been classified as a class I carcinogen by the WHO, and the eradication of $H$ pylori has been shown to treat or prevent important diseases such as peptic ulcer, mucosa-associated lymphoid tissue lymphoma and gastric adenocarcinoma (3-5). The standard course of triple therapy consists of clarithromycin with either metronidazole or amoxicillin plus a proton pump inhibitor (PPI), and is one of the most commonly used treatments for $H$ pylori (6); however, questions remain regarding the optimal duration of therapy.

Recent data suggest that the treatment success rate of $H$ pylori is declining and is dropping below the recommended eradication rate of

\author{
La trithérapie de 14 jours supérieure à celle de dix \\ jours pour éradiquer l'Helicobacter pylori : une \\ étude canadienne sur le terrain
}

HISTORIQUE : L'éradication de l'Helicobacter pylori par la trithérapie classique d'inhibiteur de la pompe à protons (IPP) pendant sept jours est en décroissance. Le prolongement de la thérapie à dix ou 14 jours s'associe à de meilleurs taux d'éradication.

OBJECTIF : Comparer l'efficacité de la trithérapie de 14 jours à celle de dix jours pour traiter l'H pylori au Canada.

MÉTHODOLOGIE : Des patients consécutifs naïs au traitement ayant des indications cliniques d'éradication de l'H pylori ont suivi une trithérapie d'IPP pendant dix ou 14 jours selon la date de leur consultation (traitement de dix jours s'ils avaient consulté à une date impaire et de 14 jours s'ils avaient consulté à une date paire). Les chercheurs ont évalué l'éradication de l'H pylori par le test respiratoire à l'urée ou des biopsies gastriques effectuées au moins quatre semaines après la fin du traitement. Ils ont procédé à des analyses de l'intention de traiter et conformes au protocole.

RÉSULTATS : Au total, 83 patients ont participé à l'étude (31 dans le groupe de dix jours et 52 dans celui de 14 jours). Dans l'analyse de l'intention de traiter, le taux d'éradication s'élevait à 82,7 \% (95\% IC $70 \%$ à $92 \%$ ) par rapport à 45,2\% (95\% IC $27 \%$ à $64 \%)$, ce qui favorisait le traitement de 14 jours $(\mathrm{P}<0,001)$. De même, dans l'analyse conforme au protocole, le taux d'éradication s'élevait à 91,5 \% (95 \% IC $80 \%$ à $98 \%$ ) par rapport à 63,6 \% (95\% IC $41 \%$ à $83 \%)$, ce qui favorisait également le volet de 14 jours $(\mathrm{P}=0,01)$. Les événements indésirables et l'adhérence ne différaient pas de manière significative entre les deux groupes.

CONCLUSION : Une trithérapie d'IPP standard de 14 jours était supérieure au traitement plus court et devrait devenir la posologie de première ligne pour éradiquer l'H pylori au Canada. Le traitement de dix jours ne s'associait pas à un taux d'éradication acceptable et ne devrait plus être utilisé au pays.

$80 \%$ (6). This decrease is likely due to antibiotic resistance; nevertheless, many suspect that the antibiotic resistance could be overcome with longer duration therapy. In fact, our group recently demonstrated that a 14-day regimen of triple therapy is superior to a seven-day regimen, with intention-to-treat (ITT) eradication rates of $85 \%$ and $70 \%$, respectively $(\mathrm{P} \leq 0.001)(7)$. A previous meta-analysis has also shown an improved eradication rate with a 10 -day treatment; however, it remains unclear whether it is as effective as a 14-day course (8), and whether either duration of PPI triple therapy achieves a sufficiently high eradication rate to still be recommended as a first-line treatment choice in North America.

The present study compared the effectiveness of a 14-day course with a 10-day triple therapy regimen in eradicating $H$ pylori in a realworld setting.

Division of Gastroenterology and Hepatology, McGill University Health Centre, McGill University, Montreal, Quebec

Correspondence: Dr Carlo A Fallone, Division of Gastroenterology, The McGill University Health Centre, Royal Victoria Hospital site, 1001 Decarie

Boulevard, Room D5.7154, Montreal, Quebec H4A 3J1. Telephone 514-934-1934 ext 36538, fax 514-843-1421, e-mail carlo.fallone@mcgill.ca Received for publication March 28, 2015. Accepted June 14, 2015 
TABLE 1

Baseline characteristics according to treatment allocation

\begin{tabular}{lcc}
\hline & \multicolumn{2}{c}{ Treatment course } \\
\cline { 2 - 3 } Characteristic & $\mathbf{1 0}$ days $\mathbf{( n = 3 1 )}$ & $\mathbf{1 4}$ days $\mathbf{( n = 5 2 )}$ \\
\hline Age, years, mean \pm SD & $66 \pm 13$ & $61 \pm 14$ \\
Female sex & $16(52) ; 33-70$ & $24(46) ; 32-60$ \\
Race & & \\
Caucasian & $28(90) ; 74-98$ & $49(94) ; 84-99$ \\
Black & $0(0) ; 0-17$ & $1(2) ; 0-10$ \\
Asian & $3(10) ; 2-26$ & $2(4) ; 0-13$ \\
Region of birth* & & \\
Eastern and Western Europe & $17(55) ; 36-73$ & $33(66) ; 51-79$ \\
The Americas & $8(26) ; 12-45$ & $10(20) ; 10-34$ \\
Other & $6(19) ; 7-37$ & $7(14) ; 6-27$ \\
Treatment setting & & \\
University hospital office & $19(61) ; 42-78$ & $35(67) ; 53-80$ \\
Community office & $12(39) ; 22-58$ & $17(33) ; 20-47$ \\
Indication & & \\
Nonulcer dyspepsia & $7(23) ; 10-41$ & $7(13) ; 6-26$ \\
Uninvestigated dyspepsia & $1(3) ; 0-17$ & $8(15) ; 7-28$ \\
Peptic ulcer disease & $3(10) ; 2-26$ & $6(12) ; 4-23$ \\
Gastroesophgeal reflux & $5(16) ; 5-34$ & $12(23) ; 13-37$ \\
Anemia & $9(29) ; 14-48$ & $9(17) ; 8-30$ \\
Family history of gastric cancer & $2(6) ; 1-21$ & $3(6) ; 1-16$ \\
Other & $4(13) ; 4-30$ & $7(13) ; 6-26$ \\
Eradication confirmatory test & & \\
Urea breath test & $21(95) ; 77-100$ & $41(87) ; 74-95$ \\
Histology/endoscopy & $1(5) ; 0-23$ & $6(13) ; 5-26$ \\
\hline Data present & & \\
\hline
\end{tabular}

Data presented as $n$ (\%); $95 \% \mathrm{Cl}$ unless otherwise indicated. ${ }^{*}$ Missing data in 2 patients

\section{METHODS}

Consecutive adult patients who were seen in the senior investigator's (CF, the only physician involved in patient recruitment) offices at either the McGill University Health Centre, or in the community (both in Montreal, Quebec) from March 2012 to April 2014, with clinical indications for $\mathrm{H}$ pylori eradication were included in the study. The diagnosis of $\mathrm{H}$ pylori was made according to histology (from endoscopic biopsies) or using urea breath test (UBT). Patients with allergies to medications used in the present study or previous treatment of $\mathrm{H}$ pylori were excluded. The institution approved the present study.

The antibiotic regimen used in the present study consisted of standard triple therapy: lansoprazole $30 \mathrm{mg}$, amoxicillin $1000 \mathrm{mg}$ and clarithromycin $500 \mathrm{mg}$, all twice daily. A prescription was provided to the patient and the medication dispensed by the patient's own pharmacist. The patient underwent either a 10-day course or a 14-day course of therapy depending on the date of the office visit, such that subjects who were seen on odd-number dates received the 10-day treatment while those who were seen on even-number dates received the 14-day treatment. Investigators and treating physicians had no influence on determining the date of the clinic visit. All subjects were encouraged to complete the full course of treatment and common side effects were explained. Side effects and compliance were documented on follow-up visit or telephone call by the nurse.

The primary outcome of the present study was the success of $H$ pylori eradication, which was ascertained $\geq 4$ weeks after completion of treatment via UBT or, in cases in which gastroscopy was indicated for other reasons, by histological examination (including Giemsa stain if negative on hematoxylin and eosin) of at least two antral and two body mucosal biopsies obtained through endoscopy. PPIs were held for two weeks before either endoscopic examination or UBT and physicians interpreting the results were blinded to the treatment allocation. Secondary end points include rate of adverse reactions and compliance to therapy.
TABLE 2

Eradication rates according to treatment allocation using intention-to-treat (ITT) and per-protocol (PP) analyses

\begin{tabular}{lccc}
\hline & \multicolumn{2}{c}{ Success rate, \% (n/n; 95\% CI) } & \\
\cline { 2 - 3 } Analysis & 10-day & 14-day & $\mathbf{P}$ \\
\hline ITT & $45.2(14 / 31 ; 27-64)$ & $82.7(43 / 52 ; 70-92)$ & 0.0006 \\
PP & $63.6(14 / 22 ; 41-83)$ & $91.5(43 / 47 ; 80-98)$ & 0.0134 \\
\hline
\end{tabular}

\section{Statistical analysis}

Continuous variables were expressed as mean $\pm \mathrm{SD}$, while $95 \%$ CIs were calculated for categorical variables using the standard normal approximation of the binomial distribution. Statistical analysis was performed using both an ITT principle, in which a patient with missing eradication data was considered to be a treatment failure, and a per-protocol (PP) analysis, in which a patient with missing eradication data was excluded from the calculation. Between-group comparisons were performed using the $\chi^{2}$ or Fisher's exact test as appropriate; statistical significance was set at $\mathrm{P}<0.05$.

\section{RESULTS}

Overall, there were a total of 83 patients included in the present study, with 31 and 52 subjects in the 10-day and 14-day treatment groups, respectively. The mean $( \pm$ SD) ages were $66 \pm 13$ years for individuals in the 10-day treatment arm and $61 \pm 14$ years for those in the 14 -day treatment arm. There were 40 female subjects $(48.2 \%)$, with the majority of participants of Caucasian background; however, >16 countries of birth were represented, reflecting the cultural diversity of Montreal. Indications for $H$ pylori eradication included nonulcer dyspepsia $(n=14)$, uninvestigated dyspepsia $(n=9)$, peptic ulcer disease $(n=9)$, gastroesophageal reflux $(n=17)$, anemia $(n=18)$, family history of gastric cancer $(n=5)$ and other indications $(n=11)$. Most patients $(n=54[65.1 \%])$ were treated and followed at a tertiary care centre, while $29(34.9 \%)$ were treated at a community office in Montreal. The patients from the community were more often female $(66 \%$ versus $41 \%$ ), Caucasian (100\% versus $89 \%$ ), and from Europe or America (100\% versus $72 \%$ ) compared with those from the University centre; however, the proportion of patients from these centres in the two treatment groups were similar (39\% versus 33\% from the community in the 10-day versus 14-day treatment groups, respectively). Table 1 summarizes the baseline characteristics of the study population, which were similar between the two treatment groups.

In terms of primary outcome, the 14-day treatment group achieved significantly higher $\mathrm{H}$ pylori eradication rates then the 10 -day treatment group. In the ITT analysis, eradication rates were $82.7 \%(95 \%$ CI $70 \%$ to $90 \%$ ) versus $45.2 \%$ (95\% CI $27 \%$ to $64 \%$ ), favouring the 14-day treatment course $(\mathrm{P}=0.0006)$ (Table 2$)$. Similarly, in the PP analysis, eradication rates were $91.5 \%$ (95\% CI $80 \%$ to $98 \%$ ) versus $63.6 \%$ (95\% CI $41 \%$ to $83 \%$ ), favouring the 14 -day treatment arm $(\mathrm{P}=0.0134)$ (Figure 1). Overall, there were 14 patients who were lost to follow-up, with nine and five patients in the 10-day and 14-day treatment groups, respectively.

There were eight adverse events related to $H$ pylori eradication therapy including nausea/vomiting $(n=3)$, diarrhea $(n=2)$, constipation $(n=1)$ and other $(n=2)$. Adverse events and compliance were not significantly different between the two groups (Table 3). Note, however, that there were significant missing data for the rate of compliance in each arm.

\section{DISCUSSION}

Our study demonstrated that a 14-day course of standard triple therapy for $H$ pylori with lansoprazole, amoxicillin and clarithromycin was superior to a 10-day regimen in achieving eradication. Allocation was determined by the date of the clinic visit with patient receiving the 10-day therapy if seen on odd-number dates and the 14-day therapy if assessed on even-number dates. Success of $H$ pylori eradication was ascertained by UBT or repeat endoscopy with histological assessment. 
Triple therapy for $H$ pylori requires 14 days

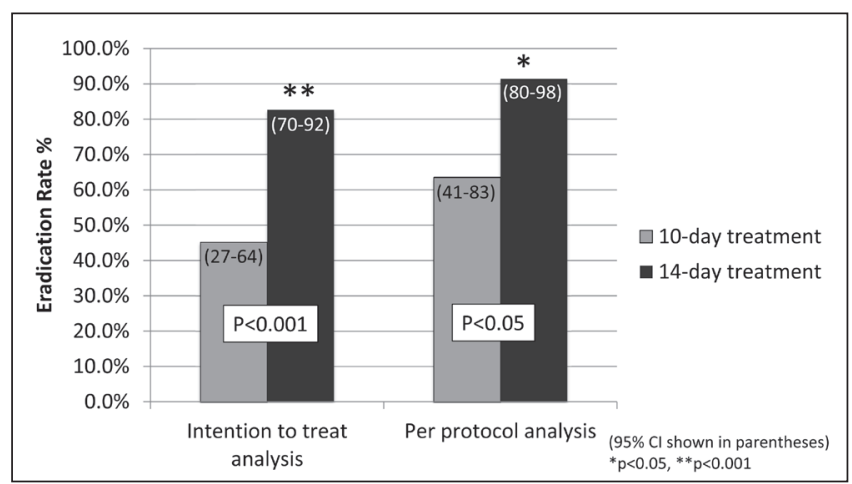

Figure 1) Proportion of successful eradication in patients who underwent a 10-day course versus a 14-day course of traditional proton pump inhibitor triple therapy in both intention to treat and per-protocol analyses. 95\% CIs are shown in parentheses. $* P<0.05 ; * * P<0.001$

In the ITT analysis, eradication rates were $82.7 \%$ (95\% CI $70 \%$ to $92 \%$ ) versus $45.2 \%$ (95\% CI $27 \%$ to $64 \%$ ) $(\mathrm{P}<0.001)$, favouring the 14-day treatment course while the PP analysis also demonstrated superiority of the 14-day treatment, with an eradication rate of $91.5 \%$ (95\% CI 80\% to $98 \%$ ) versus $63.6 \%$ (95\% CI 41\% to $83 \%)(\mathrm{P}<0.05)$.

As mentioned, epidemiological data suggest that the success of $H$ pylori eradication is on the decline and appears to be dropping below the recommended $80 \%$ eradication rate, which is postulated to be due to clarithromycin resistance (6). Our group recently demonstrated that this higher failure rate could be overcome with longer duration therapy and showed that a 14-day triple therapy regimen was superior to a seven-day therapy, with ITT eradication rates of $85 \%$ and $70 \%$, respectively (7). However, at the time of the study, it remained unclear whether a 10-day course of therapy could achieve similar success and, to our knowledge, no direct comparisons had been made between the 14-day triple therapy regimen and 10-day therapy in Canada. Our data strongly suggest that a 14-day treatment length is superior to a 10-day regimen, which is consistent with the conclusions of a recent Cochrane meta-analysis on the subject (9). Interestingly, in our study, the 10-day treatment arm did not reach the recommended eradication rate of $80 \%$, suggesting that a 14 -day treatment course is the more appropriate first-line regimen in North America.

Although there was a trend toward more adverse events with the 14-day treatment when compared with 10-day therapy, these side effects were mild, with no documented serious adverse events. The difference between the two groups did not reach statistical significance, although a larger sample size may have yielded such a difference. In those not lost to follow-up, compliance was excellent and did not differ between the two patient groups. This high compliance rate and patient tolerability is consistent with our previous data demonstrating similar results with PPI triple therapy of seven and 14 days' duration (7). As with any medical intervention, patient education and good communication are some of the most important determinants of patient compliance (10).

Several other therapeutic options have been studied in the management of $H$ pylori infection including bismuth quadruple therapy, levofloxacin-based triple therapy, sequential therapy and concomitant quadruple therapy. Bismuth quadruple therapy has a large pill burden, with possibly resultant less compliance and potentially more side effects. Levofloxacin triple therapy (combined with amoxicillin and PPI) is limited by the growing rates of levofloxacin resistance $(11,12)$. Sequential 10-day therapy, which consists of five days of amoxicillin and PPI followed by five days of tinidazole, clarithromycin and a PPI has been shown to be superior (mostly Italian patients) to the standard seven-day triple therapy $(13,14)$. However, this may be explained, in part, by the high clarithromycin resistance rate in Italy and, more importantly, may be merely due to the longer duration of treatment with the sequential therapy. In fact, a Latin American study (15) demonstrated a higher $H$ pylori eradication rate with the 14-day standard
TABLE 3

Adverse events and compliance according to treatment allocation

\begin{tabular}{lccc}
\hline Adverse events & \multicolumn{2}{c}{$\%(\mathbf{n} / \mathbf{n} ; \mathbf{9 5 \%} \mathbf{~ C l})$} & \multirow{2}{*}{$\mathbf{P}$} \\
\cline { 2 - 3 } and compliance & 10-day & 14-day & 0.7038 \\
\hline All adverse events & $6.5(2 / 31 ; 1-21)$ & $11.5(6 / 52 ; 4-23)$ & \\
Nausea/vomiting & $6.5(2 / 31 ; 1-21)$ & $1.9(1 / 52 ; 0-10)$ & \\
Diarrhea & $0(0 / 31 ; 0-17)$ & $3.8(2 / 52 ; 0-13)$ & \\
Constipation & $0(0 / 31 ; 0-17)$ & $1.9(1 / 52 ; 0-10)$ & \\
Other & $0(0 / 31 ; 0-17)$ & $3.8(2 / 52 ; 0-13)$ & \\
Compliance & $100\left(14 / 14^{*} ; 66-100\right)$ & $96.7\left(29 / 30^{*} ; 83-100\right)$ & 1.0000 \\
\hline
\end{tabular}

${ }^{*}$ Compliance rates had significant data missing in both groups, which were excluded from the calculation

triple therapy regimen when compared with the 10-day sequential therapy. Finally, different quadruple concomitant therapies have been studied and showed promising results with eradication rates as high as 92\% (16). However, both sequential therapy and quadruple concomitant therapy exposes the patient to a greater number of antibiotics, which can potentially increase the risk for treatment side effects, Clostridium difficile infection and the development of multidrug-resistant H pylori.

Limitations to our study include the fact that subjects and physicians were not blinded to the treatment allocation. However, individuals assessing the success of eradication were blinded to the treatment assignment. In addition, this was not a true randomized trial. Furthermore, more patients were assigned to the 14-day treatment arm due to the fact that the recruitment physician happened to have more assigned clinic time on even dates (in which patients were allocated to the 14-day treatment arm), which may or may not have resulted in unintentional selection bias. The community patients tended more to be Caucasian and from Europe or Canada. One cannot exclude the possibility that their infection may, therefore, have different susceptibility profiles than the patients from the University Centre; however, the distribution of these patients was not significantly different between the two treatment groups. Finally, there are some restrictions to the generalizability of the present study given that all patients were from Montreal and its surrounding areas, meaning that our results may not be applicable to areas with different antibiotic susceptibility profiles; however, our study population was quite diverse, with 16 different countries of birth represented. Finally, the present study was quite small, with only 83 patients in total, which may have been underpowered to detect differences in adverse events. However, our results are consistent with our previous, larger study comparing a 14-day regimen with a seven-day regimen, which did not show a statistical significant difference in adverse events.

The main strength of our study was its 'real-world' setting, where patients were given a prescription, which was then dispensed to them by their local pharmacists. This 'real-world' setting strengthens our data on patient compliance given that there was less potential for influences from study personnel, which are more likely to occur in a formal randomized trial. The quasirandomization also enabled us to directly compare between the 14-day arm and the 10-day group, while the fact that all consecutive patients were included likely limited possible confounders.

\section{CONCLUSION}

Our study demonstrated the superiority of a 14-day course of standard triple therapy over a 10 -day standard therapy in the eradication of $\mathrm{H}$ pylori. Furthermore, there were no significant differences in adverse reactions or compliance between both groups. Our data highly supports the use of 14-day standard triple therapy as a firstline treatment for $\mathrm{H}$ pylori in North America, with ITT and PP eradication rates of $82.7 \%$ and $91.5 \%$, respectively. The 10 -day treatment did not achieve an acceptable eradication rate and should no longer be used in Canada. 
ACKNOWLEDGEMENTS: The authors thank Normal Baysa for nursing care and data entry and Myriam Martel for statistics calculation.

FUNDING: No funding was received for this study.

DISCLOSURES: C Fallone has served as a consultant on the advisory board for Actavis, Janssen and Takeda. Yen-I Chen has no financial disclosures or conflicts of interest to declare.

\section{REFERENCES}

1. Megraud F, Brassens-Rabbe MP, Denis F, Belbouri A, Hoa DQ. Seroepidemiology of Campylobacter pylori infection in various populations. J Clin Microbiol 1989;27:1870-3.

2. Marshall BJ, Warren JR. Unidentified curved bacilli in the stomach of patients with gastritis and peptic ulceration. Lancet 1984;1:1311-5.

3. Ford AC, Forman D, Hunt RH, Yuan Y, Moayyedi P. Helicobacter pylori eradication therapy to prevent gastric cancer in healthy asymptomatic infected individuals: Systematic review and metaanalysis of randomised controlled trials. BMJ 2014:348:g3174.

4. Graham DY, Lew GM, Klein PD, et al. Effect of treatment of Helicobacter pylori infection on the long-term recurrence of gastric or duodenal ulcer. A randomized, controlled study. Ann Intern Med 1992;116:705-8.

5. Lee SK, Lee YC, Chung JB, et al. Low grade gastric mucosa associated lymphoid tissue lymphoma: Treatment strategies based on 10 year follow-up. World J Gastroenterol 2004;10:223-6.

6. Graham DY, Fischbach L. Helicobacter pylori treatment in the era of increasing antibiotic resistance. Gut 2010;59:1143-53.

7. Fallone CA, Barkun AN, Szilagyi A, et al. Prolonged treatment duration is required for successful Helicobacter pylori eradication with proton pump inhibitor triple therapy in Canada.

Can J Gastroenterol 2013;27:397-402.

8. Fuccio L, Minardi ME, Zagari RM, Grilli D, Magrini N, Bazzoli F. Meta-analysis: Duration of first-line proton-pump inhibitor based triple therapy for Helicobacter pylori eradication. Ann Intern Med 2007;147:553-62.

9. Yuan Y, Ford AC, Khan KJ, et al. Optimum duration of regimens for Helicobacter pylori eradication. Cochrane Database Syst Rev 2013;12:CD008337.

10. Jin J, Sklar GE, Min Sen Oh V, Chuen Li S. Factors affecting therapeutic compliance: A review from the patient's perspective. Ther Clin Risk Manag 2008;4:269-86.

11. Malfertheiner P, Megraud F, O'Morain CA, et al. Management of Helicobacter pylori infection - the Maastricht IV/ Florence Consensus Report. Gut 2012;61:646-64.

12. Molina-Infante J, Perez-Gallardo B, Fernandez-Bermejo M, et al. Clinical trial: Clarithromycin vs. levofloxacin in first-line triple and sequential regimens for Helicobacter pylori eradication. Aliment Pharmacol Ther 2010;31:1077-84.

13. Gisbert JP, Calvet X, O'Connor A, Megraud F, O'Morain CA. Sequential therapy for Helicobacter pylori eradication: A critical review. J Clin Gastroenterol 2010;44:313-25.

14. Nyssen O, McNicholl A, Megraud F, et al. Meta-analysis of sequential versus standard triple therapy for Helibacter pylori eradication: Final results of a Cochrane Systemic Review. . Gastroenterology 2014;146(Suppl 1):S393.

15. Greenberg ER, Anderson GL, Morgan DR, et al. 14-day triple, 5-day concomitant, and 10-day sequential therapies for Helicobacter pylori infection in seven Latin American sites: A randomised trial. Lancet 2011;378:507-14.

16. Federico A, Nardone G, Gravina AG, et al. Efficacy of 5-day levofloxacin-containing concomitant therapy in eradication of Helicobacter pylori infection. Gastroenterology 2012;143:55-61. 


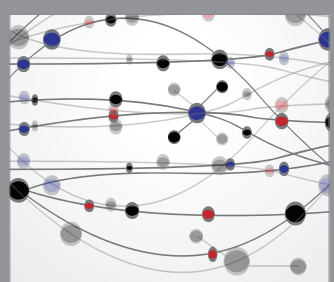

The Scientific World Journal
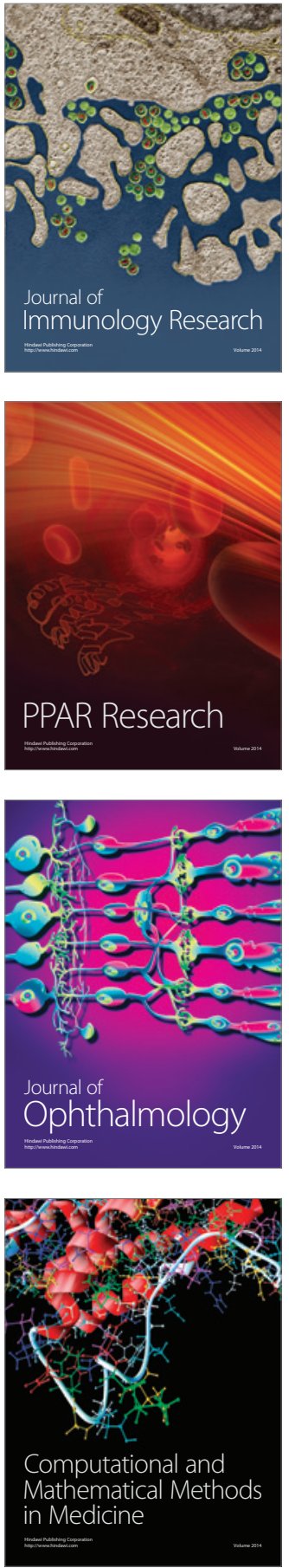

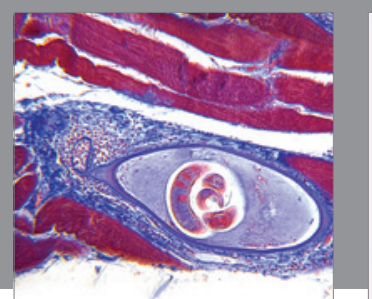

Gastroenterology Research and Practice

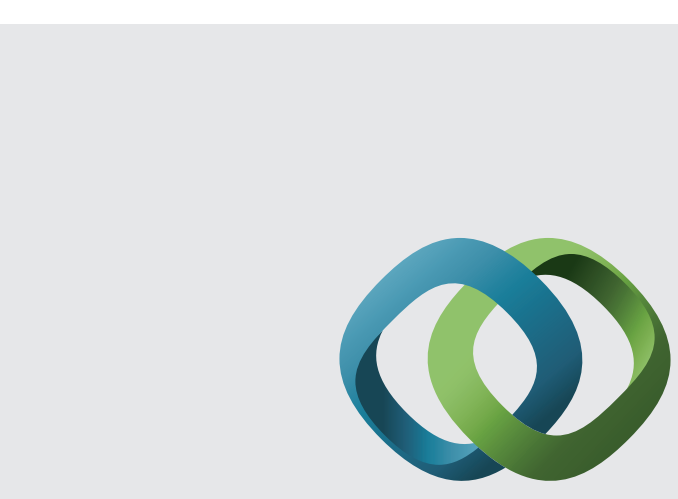

\section{Hindawi}

Submit your manuscripts at

http://www.hindawi.com
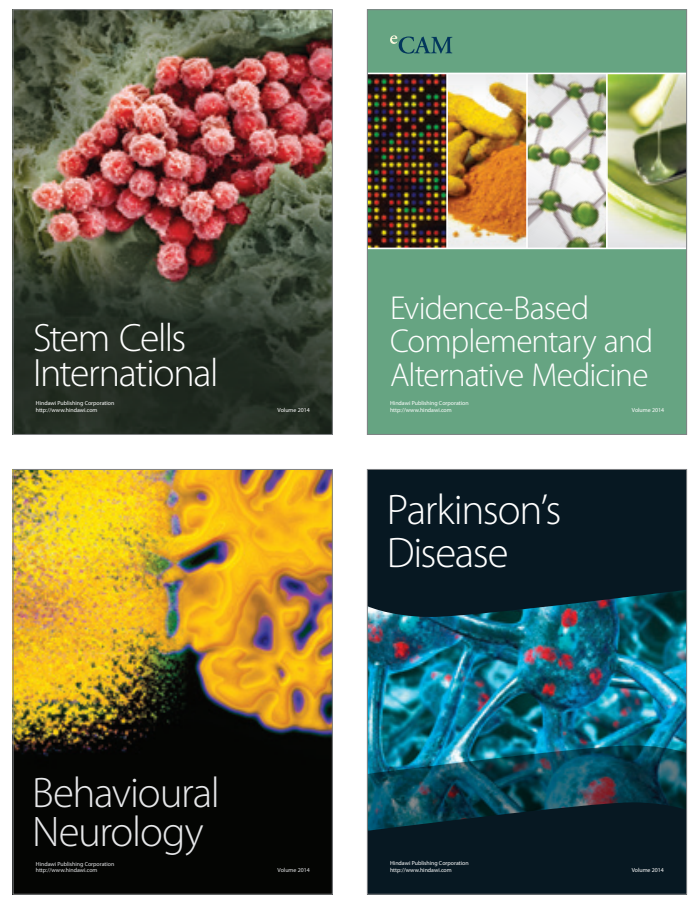
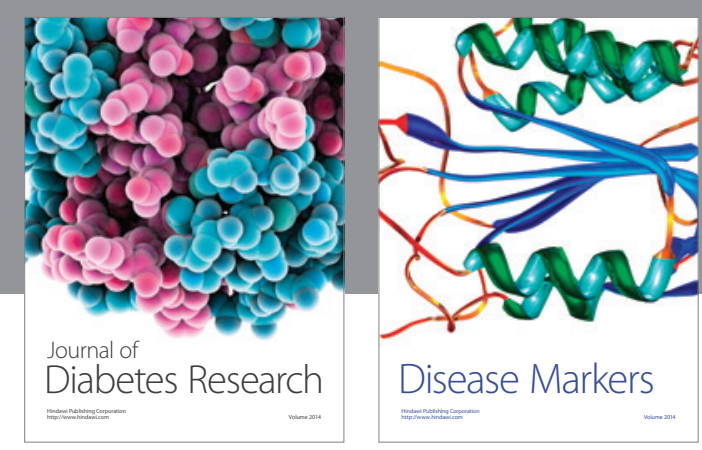

Disease Markers
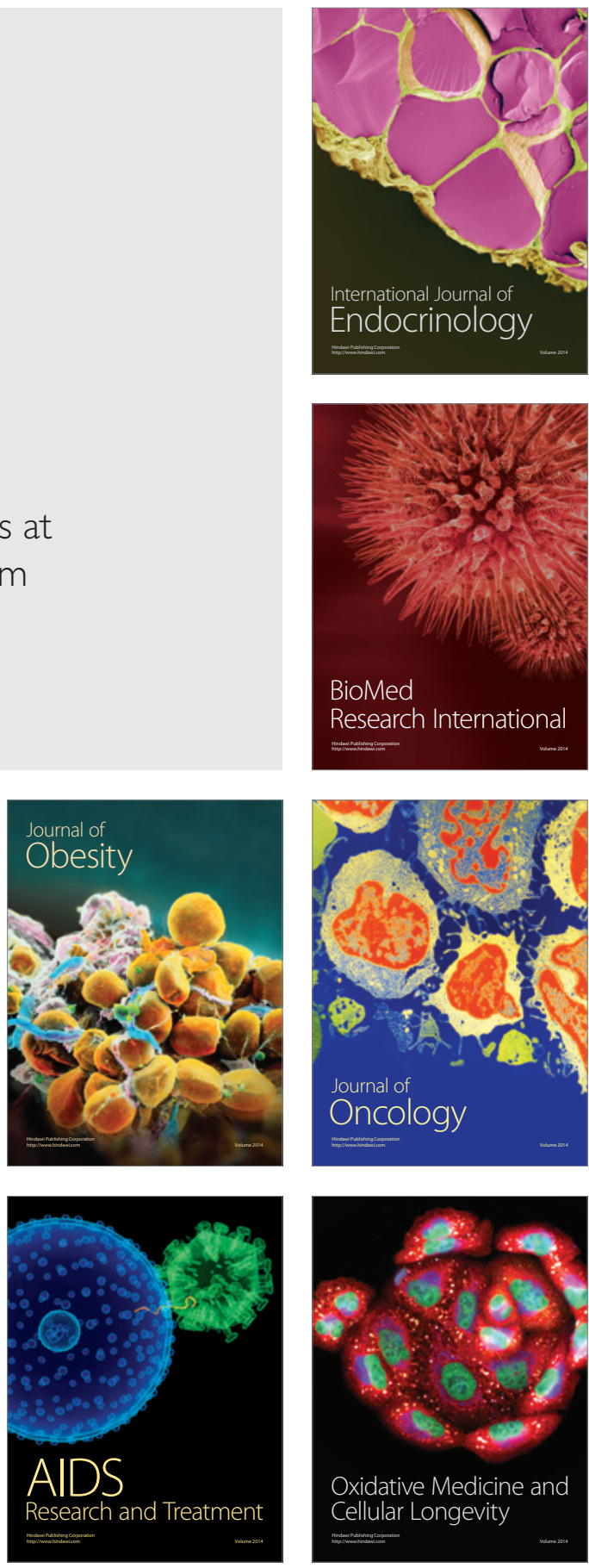